\title{
An IL-15 Superagonist, ALT-803, Enhances Antibody-Dependent Cell-Mediated Cytotoxicity Elicited by the Monoclonal Antibody NEO-201 Against Human Carcinoma Cells
}

\author{
Massimo Fantini, ${ }^{1}$ Justin M. David, ${ }^{1}$ Hing C. Wong, ${ }^{2}$ Christina M. Annunziata, ${ }^{3}$ \\ Philip M. Arlen, ${ }^{1}$ and Kwong Y. Tsang ${ }^{1}$
}

\begin{abstract}
Background: A major mechanism of action for therapeutic antibodies is antibody-dependent cell-mediated cytotoxicity (ADCC). ALT-803 is an interleukin-15 superagonist complex that enhances ADCC against human carcinoma cells in vitro and exerts an antitumor activity in murine, rat, and human carcinomas in vivo. The authors investigated the ability of ALT-803 to modulate ADCC mediated by the humanized IgG1 monoclonal antibody (mAb) NEO-201 against human carcinoma cells.

Materials and Methods: ALT-803 modulating activity on ADCC mediated by NEO-201 was evaluated on several NEO-201 ligand-expressing human carcinoma cells. Purified human natural killer (NK) cells from multiple healthy donors were treated with ALT-803 before their use as effectors in ADCC assay. Modulation of NK cell phenotype and cytotoxic function by exposure to ALT-803 was evaluated by flow cytometry and gene expression analysis. Results: ALT-803 significantly enhanced ADCC mediated by NEO-201. ALT-803 also upregulated NK activating receptors, antiapoptotic factors, and factors involved in the NK cytotoxicity, as well as downregulated gene expression of NK inhibiting receptors.

Conclusions: These findings indicate that ALT-803 can enhance ADCC activity mediated by NEO-201, by modulating NK activation and cytotoxicity, suggesting a possible clinical use of ALT-803 in combination with NEO-201 for the treatment of human carcinomas.
\end{abstract}

Keywords: antibody-dependent cell-mediated cytotoxicity, IL-15 superagonist, immunostimulation, monoclonal antibody, NEO-201, natural killer cells

\section{Introduction}

C onventional cancer therapies, such as surgery, radiation, and chemotherapy, are usually effective in treating patients with the primary tumors, but often fail in treating metastatic disease. ${ }^{1,2}$ The development of immunotherapies for cancer has led to prolonged clinical responses in metastatic disease, even when traditional therapies have failed. ${ }^{3}$ The immune system suppresses the proliferation of cancer cells, recognizing cancer-specific antigens, and activating various cytotoxic programs, through a process called immunoediting of the cancer cells. ${ }^{4}$ However, cancer cells may escape the selective pressure of the immune system, generating a more malignant phenotype with the ability to spread to different parts from the primary site (in a process known as metastasis). ${ }^{5}$ The aim of cancer immunotherapy is to enhance antitumor immune responses to control the growth of both the primary tumor and cancer cells present in the blood circulation and metastases in distant organs. ${ }^{6-10}$

\footnotetext{
${ }^{1}$ Precision Biologics, Inc., Rockville, Maryland.

${ }^{2}$ Altor BioScience Corporation, Miramar, Florida.

${ }^{3}$ Women's Malignancy Branch, Center for Cancer Research, National Cancer Institute, National Institutes of Health, Bethesda, Maryland.

Address correspondence to: Kwong Y. Tsang; Precision Biologics, Inc.; 9600 Medical Center Drive, Suite 300, Rockville, MD 20850 E-mail: al.tsang@precision-biologics.com

(c) Massimo Fantini, et al., 2019; Published by Mary Ann Liebert, Inc. This Open Access article is distributed under the terms of the Creative Commons License (http://creativecommons.org/licenses/by/4.0), which permits unrestricted use, distribution, and reproduction in any medium, provided the original work is properly cited.
} 
Cellular subsets within the innate immune system, including natural killer (NK) cells, play a significant role in cancer immunosurveillance, and monoclonal antibodies (mAbs) in combination with immunostimulants can enhance innate antitumor immunity. ${ }^{10,11}$ Several studies have shown the antitumor potential of NK cells, demonstrating the potential value of NK cell-based immunotherapies as a new frontier in cancer treatment. ${ }^{12-14}$

NK cell antitumor activity can be modulated by the use of cytokines. The cytokine interleukin-15 (IL-15) plays a crucial role in the immune system by affecting NK cell development, proliferation, cytotoxicity, and cytokine production. ${ }^{15}$ IL-15 binds to the IL- $15 \mathrm{R} \alpha$ present on the surface of monocytes or dendritic cells, and is presented to NK and $\mathrm{CD}^{+} \mathrm{T}$ cells where it forms a complex with IL-15R $\beta$ to activate several intracellular signaling pathways, such as the PI3K-AKT-mTOR pathway. ${ }^{16,17}$

Technologies based on IL-15's immunomodulatory properties have also been developed, including the IL-15 superagonist complex (ALT-803). ALT-803 consists of an IL-15 variant (IL-15N72D) bound to an IL-15 receptor $\alpha /$ IgG1 Fc fusion protein, resulting in improved stability, longer persistence in lymphoid tissues, and enhanced antitumor activity compared to native IL-15 in vivo. ${ }^{18}$

ALT-803 was found to enhance antibody-dependent cellmediated cytotoxicity (ADCC) against a wide range of human carcinoma cells in vitro. ${ }^{19-21}$ ALT-803 also exerted a significant antitumor activity in murine models of multiple myeloma, glioblastoma, ovarian cancer, and in murine breast, colon, and melanoma tumor-bearing mice. ${ }^{22-26}$ Moreover, intravesical ALT-803 and Bacillus Calmette-Guerin (BCG) administration showed a reduction of tumor burden in a bladder cancer rat model. ${ }^{27}$ Promising preclinical data on the use of ALT-803 as an anticancer drug have spurred interest in using it in the clinic. Several ongoing clinical trials are evaluating the safety and efficacy of ALT-803 alone or in combination with conventional cancer treatments. ${ }^{28-35}$

NEO-201 is a humanized IgG1 mAb that reacts to tumorassociated antigens derived from the Hollinshead allogeneic colorectal cancer vaccine platform. ${ }^{36-38}$ A preliminary study indicated that NEO-201 may recognize tumor-associated variants of CEACAM family members. ${ }^{39}$ In a previous study, the authors showed that NEO-201 is remarkably tumor specific in its staining profile and demonstrated its ability to react to a wide range of human carcinoma cell lines by flow cytometry and tumor tissues by immunohistochemistry. It has also been shown that an overwhelming majority of healthy normal tissues were found to be negative for NEO-201. ${ }^{40}$ Although NEO-201 positivity was detected in normal tongue and ectocervix tissues, the staining intensity was weak. ${ }^{39,40}$ NEO-201 administration did not induce any grossly observable toxicity in mice. A single-dose toxicity study in nonhuman primates demonstrated safety and tolerability of NEO-201, as a transient decrease in circulating neutrophils was the only related adverse effect observed. $^{40}$

In addition, NEO-201 exhibited both ADCC and complement-dependent cytotoxicity (CDC) activity against human carcinoma cells in vitro, and counteracted the growth of human pancreatic xenograft tumors in vivo. ${ }^{40}$

ADCC is mediated by binding of the constant region (fragment crystallizable, Fc) of mAbs and the Fc gamma receptor IIIa (Fcy RIIIa, CD16) expressed on macrophages and NK cells. This interaction induces macrophages to phagocytose mAb-opsonized cancer cells, and leads NK cells to lyse mAb-bounded cancer cells. ${ }^{41}$

This study was undertaken to assess the ability of ALT803 to enhance the ADCC mediated by NEO-201, employing NK cells treated with ALT-803 as effectors against human carcinoma cells. The authors demonstrated that ALT-803 significantly enhanced the ADCC activity mediated by NEO-201 against NEO-201-positive carcinoma cells in a dose-dependent manner. ALT-803 was also able to upregulate gene and protein expression of NK-activating receptors and the gene expression of antiapoptotic factors and factors involved in NK cytotoxicity, as well as to downregulate gene expression of NK-inhibiting receptors and factors involved in NK cell exhaustion, and to prolong NK cell viability.

These findings provide the rationale for the development of a potential clinical therapy using ALT-803 in combination with NEO-201 as a strategy for the treatment of NEO201-positive tumors.

\section{Materials and Methods}

\section{Cell lines and culture}

The following human carcinoma cell lines were obtained from the American Type Culture Collection (Manassas, VA): pancreas (ASPC-1 and CFPAC-1), breast (ZR-75-1), and lung (H520 and HCC827). All cell cultures were maintained in RPMI 1640 or IMDM culture medium (Corning, Corning, NY) as designated by the provider for propagation and maintenance. Culture medium was supplemented with $10 \%$ USA-sourced and heat-inactivated HyClone fetal bovine serum (FBS) defined (GE Healthcare Life Sciences, Issaquah, WA), $100 \mathrm{U} / \mathrm{mL}$ penicillin, and $100 \mu \mathrm{g} / \mathrm{mL}$ streptomycin (Corning Life Science, Manassas, VA). Peripheral blood mononuclear cells (PBMCs) from healthy volunteer donors were obtained from the National Institutes of Health Clinical Center Blood Bank (NCT00001846) under the appropriate Institutional Review Board approval and informed consent.

\section{NK cell purification}

NK effector cells were isolated from PBMCs using the EasySep Human NK Cell Isolation Kit (StemCell Technologies, Vancouver, BC, Canada) according to the manufacturer's protocol. NK cells isolated from healthy donors were treated for 24 and $48 \mathrm{~h}$ with ALT-803 (Altor BioScience, Miramar, FL) at different concentrations (6.25, 12.5 , and $25 \mathrm{ng} / \mathrm{mL}$ ) before being examined by flow cytometry, by NanoString Technologies nCounter Platform, or to be used as effectors in the ADCC assay. Untreated NK cells were used as control.

\section{Flow cytometry}

Analysis of the expression of cell surface and intracellular proteins in purified NK cells and in human carcinoma cell lines was performed by flow cytometry. Cells $\left(1.0 \times 10^{6}\right)$ were incubated with $1 \mu \mathrm{L}$ per test of LIVE/DEAD Fixable Aqua (Thermo Fisher Scientific, Waltham, MA) in $1 \times$ phosphate buffered saline (PBS) for $30 \mathrm{~min}$ at $4^{\circ} \mathrm{C}$ to accomplish live 
versus dead cell discrimination. Cells were then centrifuged, washed twice with cold PBS, and then stained with primary antihuman mAbs in $1 \times \mathrm{PBS}+1 \%$ BSA (Teknova, Hollister, $\mathrm{CA}$ ) for $30 \mathrm{~min}$ at $4^{\circ} \mathrm{C}$. Binding of NEO-201 to human carcinoma cell lines was detected by Pacific Blue-conjugated NEO-201 antibody (BioLegend, San Diego, CA). To detect the NK markers modulated by ALT-803, purified NK cells were labeled with following antibodies: CD56-PE (clone 5.1H11), CD16-PerCP-Cy5.5 (clone 3G8), Tim-3-PE-Cy7 (clone F38-2E2), NKG2D-BV421 (clone 1D11), CD107aAPC-Cy7 (clone H4A3), Granzyme B-FITC (clone GB11), PD-1-APC (clone EH12.2H7), and CD158d-APC (clone $\mathrm{mAb} 33$ ) (BioLegend). After staining, cells were washed twice with cold PBS and examined using a FACSVerse flow cytometer (BD Biosciences, San Jose, CA). Analysis of cellular fluorescence was performed using BD FACSuite software (BD Biosciences). Positivity was determined by using fluorescence-minus-one controls.

\section{ADCC assay}

Purified NK cells were treated with ALT-803 (6.25, 12.5, and $25 \mathrm{ng} / \mathrm{mL}$ ) or vehicle control (RPMI-1640 medium supplemented with L-glutamine, 10\% FBS, and antibiotics) for $48 \mathrm{~h}$ before being used as effectors. On the day of the assay, human carcinoma cell lines (target cells) were labeled with $10 \mu \mathrm{M}$ Calcein AM cell-permeant dye (Thermo Fisher Scientific) for $30 \mathrm{~min}$ and then seeded in triplicate at $3.0 \times 10^{3}$ cells/well into black-walled flat-bottom 96-well culture plates (655090; Greiner Bio-One, Kremsmünster, Austria). Target cells were then treated with human IgG1 isotype control antibody (Thermo Fisher Scientific) or NEO201 (dose range $0.1-10 \mu \mathrm{g} / \mathrm{mL}$ ), and then, purified NK cells were added at effector-to-target (E:T) ratios of $6.25: 1$ and 12.5:1.

For blocking studies, purified NK cells were incubated at $37^{\circ} \mathrm{C}$ for $2 \mathrm{~h}$ with $15 \mu \mathrm{g} / \mathrm{mL}$ of antihuman CD16-neutralizing $\mathrm{mAb}$ (eBioscience, San Diego, CA) before being used as effectors. After $4 \mathrm{~h}$ of incubation at $37^{\circ} \mathrm{C}, 10 \mu \mathrm{g} / \mathrm{mL}$ the propidium iodide (Thermo Fisher Scientific) was added to each well and the plate was imaged and analyzed using the Celigo Imaging Cytometer (Nexcelom Bioscience LLC, Lawrence, MA). Specific ADCC lysis was calculated using the following formula: \% specific lysis $=100-[$ (average live target count experimental/average live target count control $) \times 100]$.

\section{Gene expression analysis}

The gene expression analysis of ALT-803-treated NK cells was performed using the NanoString Technologies nCounter Platform. Briefly, purified NK cells were exposed to vehicle control (RPMI-1640 medium supplemented with L-glutamine, $10 \%$ FBS, and antibiotics) or ALT-803 (6.25, 12.5 , and $25 \mathrm{ng} / \mathrm{mL}$ ) for $48 \mathrm{~h}$ before performing RNA isolation. Total RNA was purified using the RNeasy Plus Mini Kit (Qiagen, Valencia, CA). RNA extraction and purification steps were performed according to the manufacturers' instructions. RNA concentration and purity were determined using Nanodrop 2000 (Thermo Fisher Scientific). RNA was then analyzed for gene expression using the Nanostring Technologies nCounter LBL-C0269 Human Immunology v2 Panel (Nanostring Technologies, Inc., Seattle, WA).

\section{Analysis of cell viability}

To analyze the effect of ALT-803 on NK cell viability, purified NK cells from two healthy donors were exposed to vehicle control or ALT-803 $(25 \mathrm{ng} / \mathrm{mL})$ on day 0 and then returned to incubation at $37^{\circ} \mathrm{C}$ in presence of $5 \% \mathrm{CO}_{2}$ for $6 \mathrm{~d}$. Alternatively, vehicle control and ALT-803 were replenished every $2 \mathrm{~d}$.

After drug exposure, cells were harvested and viable cells were counted by AO/PI (acridine orange/propidium iodide) staining solution (Nexcelom Bioscience LLC) using the Cellometer Auto T4 automated cell counter (Nexcelom Bioscience LLC).

\section{Statistical analysis}

The distribution of cell populations by flow cytometry analyses was preliminary verified using the KolmogorovSmirnov test.

Significant differences between two treatment groups were determined by $T$-test, and differences between multiple treatment groups were evaluated by two-way ANOVA followed by Turkey's multiple comparison test, using GraphPad Prism 7.0 software (GraphPad Software, La Jolla, CA). Differences were considered significant when the $p$-value was $<0.05$.

Graphs depict the mean \pm SD from one representative experiment performed in triplicate.

\section{Results}

\section{ALT-803 enhances ADCC mediated by NEO-201 against human carcinoma cells}

To investigate the ability of ALT-803 to modulate ADCC activity mediated by NEO-201, ALT-803 was added to human NK cells isolated from PBMCs, from multiple healthy donors in the presence of several NEO-201 ligandexpressing human carcinoma cell lines. The NEO-201ligand expression profile of human carcinoma cell lines is shown in Table 1.

These NEO-201-positive human carcinoma cell lines were chosen from the panel of human carcinoma cell lines tested for NEO-201 binding reported in the previous study. 40

NEO-201-negative human carcinoma cell lines were not selected for this investigation.

Table 1. Flow Cytometry Analysis of NEO-201

Binding to Cultured Tumor Cell Lines Derived FROM VARIOUS TYPES OF SOLID TUMORS

\begin{tabular}{llcr}
\hline Tumor & Cell line & $\begin{array}{c}\% \\
\text { positive }\end{array}$ & MFI \\
\hline Pancreas & CFPAC-1 & 97.70 & 9276 \\
Squamous lung (NSCLC) & H520 & 60.51 & 247 \\
Adenocarcinoma lung & HCC827 & 73.39 & 330 \\
$\quad\left(\mathrm{NSCLC}^{+} / \mathrm{PR}^{+} / \mathrm{HER} 2^{+}\right)$ & ZR-75-1 & 51.43 & 701 \\
\hline Breast (ER & & & \\
\hline
\end{tabular}

The percentage of positive cells and median fluorescence intensity values are detailed for each cell line. NEO-201 positivity was defined as $\%$ positive $>10 \%$.

MFI, median fluorescence intensity; NSCLC, non-small-cell lung carcinoma. 
ALT-803-modulating activity on ADCC mediated by NEO201 was evaluated first on the highly NEO-201-positive CFPAC-1 cell line. Purified NK cells from one healthy donor were treated with ALT-803 $(6.25-25 \mathrm{ng} / \mathrm{mL})$ or vehicle control for $48 \mathrm{~h}$ before their use as effectors in the ADCC assay. ALT803 enhanced NEO-201-mediated ADCC against CFPAC-1 in a dose-dependent manner, compared with the vehicle control at both E:T ratios (Fig. 1). The results demonstrate that ALT-803 significantly increased the ADCC activity mediated by NEO201 at a concentration as low as $25 \mathrm{ng} / \mathrm{mL}$ (Fig. 1). For this reason, the authors chose this concentration $(25 \mathrm{ng} / \mathrm{mL})$ for the future experiments.

To determine whether ALT-803 can modulate the ADCC activity mediated by NEO-201 against other NEO-201positive cancer cells, ADCC assays were performed using four human carcinoma cell lines: pancreas (CFPAC-1), breast (ZR75-1), and lung (H520 and HCC827). Purified NK cells from additional healthy donors were treated with ALT-803 $(25 \mathrm{ng} / \mathrm{mL})$ or vehicle control for $48 \mathrm{~h}$ before being used as effectors in the ADCC assay. As shown in Figure 2, ALT-803 significantly enhanced NEO-201-mediated ADCC at both E:T ratios in all cell lines compared to untreated cells: CFPAC-1 (E:T 12.5:1, 1.66-fold increase; and E:T 6.25:1, 2.22-fold increase), ZR-75 (E:T 12.5:1, 2.15-fold increase; and E:T 6.25:1, 1.80-fold increase), H520 (E:T 12.5:1, 1.74-fold increase; and E:T 6.25:1, 1.71-fold increase), and HCC827 (E:T 12.5:1, 1.33-fold increase; and E:T 6.25:1, 1.53-fold increase). These data demonstrated that ALT-803 treatment of NK cells effectively enhances NEO-201-mediated ADCC against NE0201-positive carcinoma cells in vitro.

Treatment of NK cells with ALT-803 enhances

$A D C C$ against human carcinoma cell lines

at suboptimal doses of NEO-201

To evaluate whether ALT-803 enhances NEO-201mediated ADCC at lower antibody doses, the authors performed a NEO-201 antibody titration $(0.1,1$, and $10 \mu \mathrm{g} / \mathrm{mL})$ in the ADCC assay, using CFPAC-1 cells as target. As shown in Figure 3, titration assays revealed that NK cells treated with ALT-803 $(25 \mathrm{ng} / \mathrm{mL})$ can enhance NEO-201mediated ADCC at doses as low as $0.1 \mu \mathrm{g} / \mathrm{mL}$ compared to untreated NK cells. These data suggest that treatment of NK cells with ALT-803 could decrease the dose of NEO-201 needed to achieve its clinical efficacy if used in combination therapy.

\section{ADCC mediated by NEO-201 enhanced by treatment of NK cells with ALT-803 is dependent on CD16 engagement}

CD16 engagement has been proven to play a critical role in ADCC mediated by several mAbs clinically approved to treat cancer. ${ }^{41-47}$ To determine whether tumor cell lysis in the presence of NEO-201 is mediated by ADCC and that ALT-803 is able to enhance NEO-201-mediated ADCC, NK cells isolated from a healthy donor were treated with ALT$803(25 \mathrm{ng} / \mathrm{mL})$ or vehicle control for $48 \mathrm{~h}$. Then, the antiCD16 antibody was added to NK cells before using them in the ADCC assay. As shown in Figure 4, the anti-CD16 antibody significantly decreased ADCC activity mediated by NEO-201 of both untreated $(p<0.05)$ and ALT-803treated NK cells $(p<0.001)$, confirming that increased tumor cell lysis in presence of NEO-201 is mediated by ADCC and that ALT-803 enhances specifically NEO-201mediated ADCC.

\section{ALT-803 modulates the phenotype of human healthy donor NK cells toward a more active cytotoxic function}

Mounting evidence suggests that NK cells exhibit potent antitumor responses following IL-15 priming in humans ${ }^{15-17,24,48,49}$ and in animals. ${ }^{16,25}$ Thus, the authors sought to evaluate whether NK cell phenotype and cytotoxic function could be modulated by exposure to ALT-803. Human NK cells isolated from two healthy donors were treated with ALT-803 (25 ng/mL) or vehicle control for $48 \mathrm{~h}$

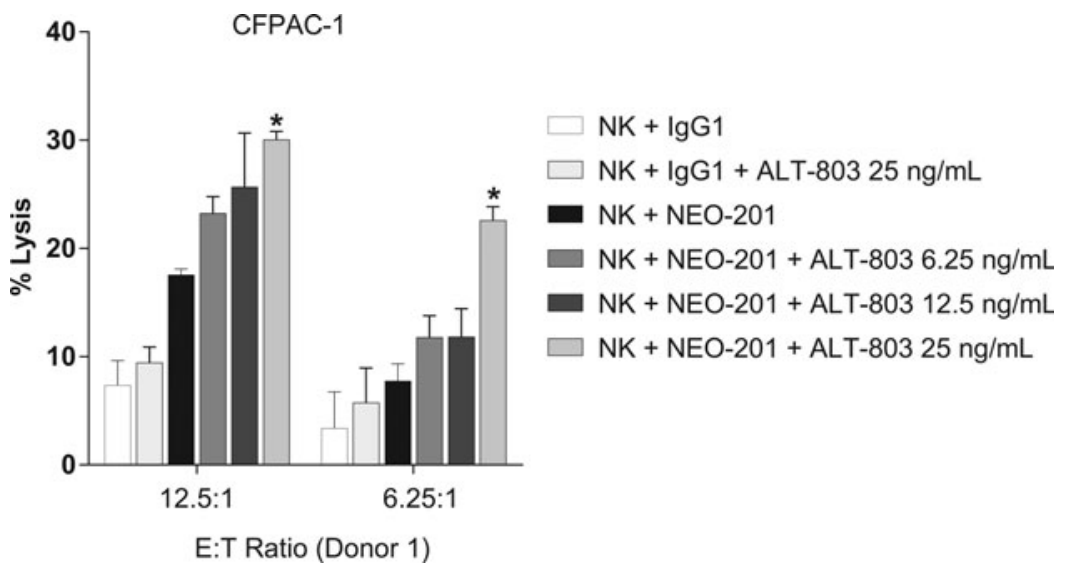

FIG. 1. ALT-803 enhances NEO-201-mediated ADCC against CFPAC-1 in a dose-dependent manner. CFPAC-1 (human pancreatic carcinoma cells) were used as target cells. NEO-201 and human IgG1 (negative control) were used at a concentration of $10 \mu \mathrm{g} / \mathrm{mL}$ of NEO-201 in ADCC assay. Purified NK cells from a healthy donor were treated with ALT-803 $(6.25-25 \mathrm{ng} / \mathrm{mL})$ or vehicle control for $48 \mathrm{~h}$ before being used as effector cells at the indicated E:T ratios. Results are presented as mean \pm S.E.M. from three replicate wells. Asterisks denote statistical significance of NK+NEO-201+ALT-803 relative to controls (NK+NEO-201; NK+IgG1+ALT-803) (two-way ANOVA). ${ }^{*} p<0.05$. ADCC, antibody-dependent cellular cytotoxicity; NK, natural killer. 

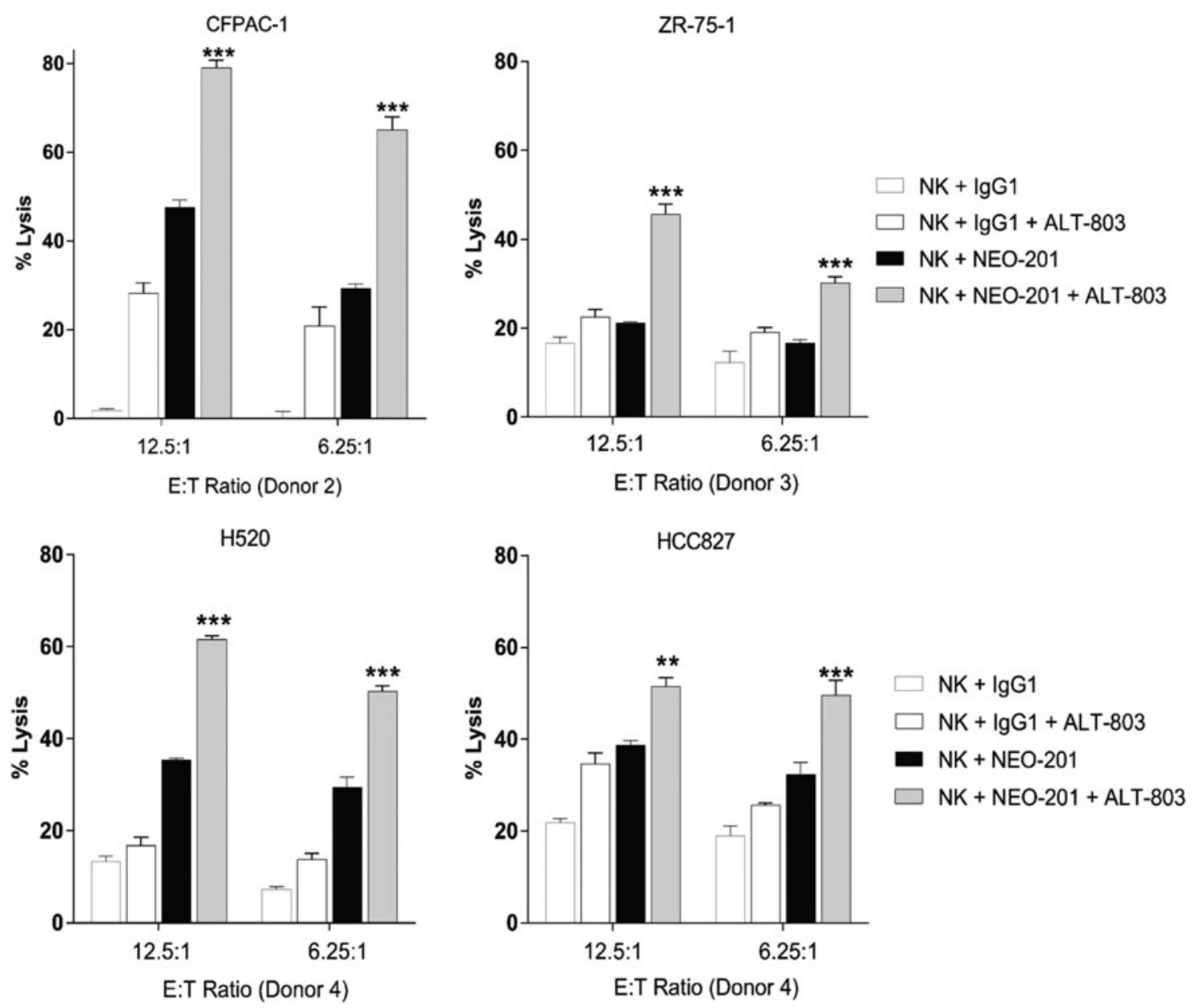

FIG. 2. ALT-803 enhances NEO-201-mediated ADCC against human carcinoma cell lines. ALT-803 enhances the ADCC activity mediated by NEO-201 against CFPAC-1, ZR-75-1, H520, and HCC827 cells. Carcinoma cells were used as target cells in the presence of $10 \mu \mathrm{g} / \mathrm{mL}$ of NEO-201 or human IgG1 (negative control) in the ADCC assay. Purified NK cells from three healthy donors were treated with ALT-803 $(25 \mathrm{ng} / \mathrm{mL})$ or vehicle control for $48 \mathrm{~h}$ before being used as effector cells at the indicated E:T ratios. Results are presented as mean \pm S.E.M. from three replicate wells. Asterisks denote statistical significance of NK+NEO-201+ALT-803 relative to controls (NK+NEO-201; NK+IgG1+ALT-803) (two-way ANOVA). $* * p<0.01 ; * * * p<0.001$. ADCC, antibody-dependent cellular cytotoxicity; NK, natural killer.

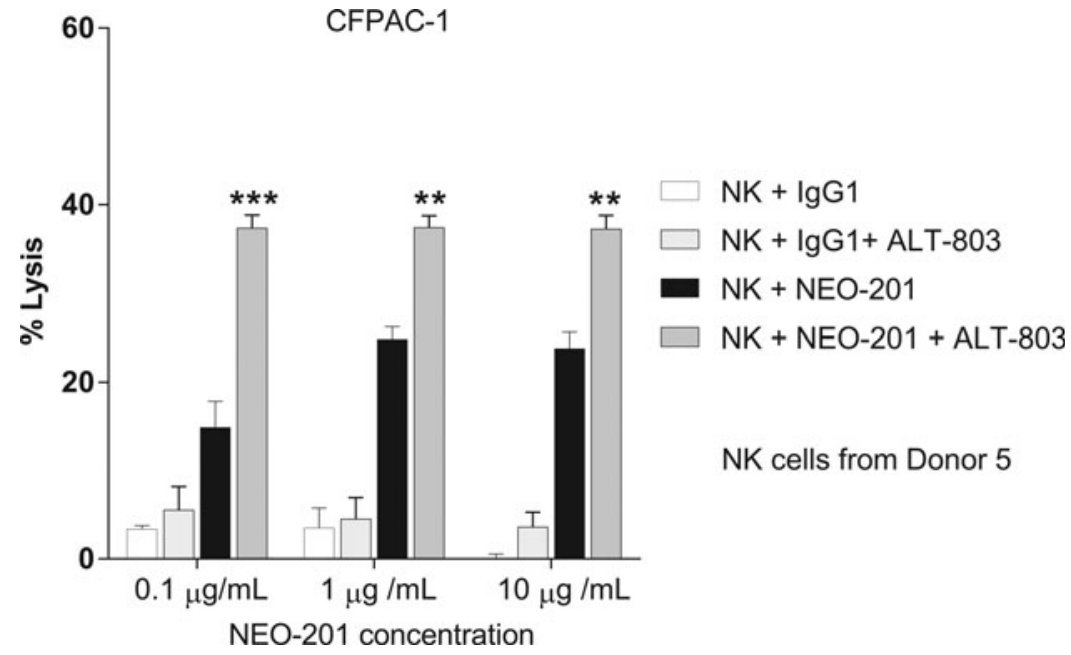

FIG. 3. Treatment of NK cells with ALT-803 enhances ADCC against human carcinoma cell lines at suboptimal doses of NEO-201. ALT-803 enhances ADCC activity mediated by NEO-201 against CFPAC-1 cells. CFPAC-1 cells were used as target cells in the presence of NEO-201 or human IgG1 (negative control) at different concentrations $(0.1-10 \mu \mathrm{g} / \mathrm{mL}) \mathrm{in}$ ADCC assay. Purified NK cells from a healthy donor were treated with ALT-803 $(25 \mathrm{ng} / \mathrm{mL})$ or vehicle control for $48 \mathrm{~h}$ before being used as effector cells at an E:T ratio of 12.5:1. Results are presented as mean \pm S.E.M. from three replicate wells. Asterisks denote statistical significance of NK+NEO-201+ALT-803 relative to NK+NEO-201 (two-way ANOVA). $* * p<0.01 ; * * * p<0.001$. ADCC, antibody-dependent cellular cytotoxicity; NK, natural killer. 
before performing phenotypical analysis. NK cells treated with ALT-803 showed an increase in TIM- $3^{+} / \mathrm{NKG}_{2} \mathrm{D}^{+}$ expression of 1.69-fold (TIM-3 median fluorescence intensity [MFI] 3.76-fold; and NKG2D MFI 1.63-fold) in Donor 7 and 3.43-fold (TIM-3 MFI 2.95-fold; and NKG2D MFI 2.32 -fold) in Donor 8 in the $\mathrm{CD} 16^{+} / \mathrm{CD} 6^{+}$population, compared to untreated cells (Table 2).

ALT-803 also induced a marked increase of CD56 and granzyme B MFI in $\mathrm{CD} 16^{+} / \mathrm{CD}^{+} 6^{+}$population in both donors (Donor 7: CD56, 3.43-fold; granzyme B, 2.84-fold. Donor 8: CD56, 2.57-fold; granzyme B, 2.12-fold) and of CD107a MFI (3.05-fold) in the $\mathrm{CD} 16^{+} / \mathrm{CD}^{2} 6^{+}$population in one donor, compared to untreated cells (Table 2 ).

\section{ALT-803 modulates the gene expression of human healthy donor NK cells}

To better understand the mechanism whereby ALT-803 modulates NK function, the authors performed a gene expression analysis on NK cells treated with ALT-803. Purified NK cells from a healthy donor were treated with ALT-803 at different concentrations $(6.25-25 \mathrm{ng} / \mathrm{mL})$ or with vehicle control for $48 \mathrm{~h}$ before performing RNA isolation. RNA from the ALT-803 cultured cells was analyzed for gene expression using Nanostring Technologies nCounter LBL-C0269 Human Immunology v2 Panel. As shown in Table 3, ALT-803 upregulated gene expression of NK-activating receptors (LAG-3 and 4-1BB) and downregulated gene expression of NK inhibitory receptors (KLRG1 and CD85C).

ALT-803 upregulated gene expression of factors involved in NK cytotoxicity (clusterin, IDO1, granzyme A and B, CD225, perforin 1, and CD56), and of cytokines/chemokines and receptors (GM-CSF, CXCL9 and 10, chemokine receptor 1 , interferon- $\gamma[$ IFN- $\gamma]$, tumor necrosis factor- $\alpha$ [TNF- $\alpha]$, TNF- $\beta$, CD30L, TRAIL, CD25, and CD122). ALT-803 also modulated gene expression of signal transduction and transcriptional factors, upregulating the mRNA transcription of the antiapoptotic protein Bcl-2 and DUSP-4, and downregulating the mRNA transcription of factors involved in NK cell exhaustion (PD-1). Altogether, these data indicate that ALT-803 is able to modulate the phenotype of human NK cells, through upregulation of gene and protein expression of $\mathrm{NK}$-activating receptors and gene expression of antiapoptotic factors and factors involved in the NK cytotoxicity, and through the downregulation of gene expression of NKinhibiting receptors and factors involved in the NK cell exhaustion.

\section{ALT-803 prolongs viability of NK cells}

To evaluate whether modulation of NK cell gene expression by ALT-803 affected NK cell viability, purified NK cells from two healthy donors were cultured with ALT-803 $(25 \mathrm{ng} / \mathrm{mL})$ or vehicle control for 6 or $10 \mathrm{~d}$. As shown in Figure 5A and B, NK cells exposed to ALT-803 for $6 \mathrm{~d}$ showed a significant increase of viability only on day 2 and 3 in both donors compared to untreated cells (Donor 9: day 2, $p=0.011$, day 3, $p=0.006$; Donor 10: day 2, $p=0.013$, day 3, $p=0.008$ ). Conversely, replenishment of ALT-803 every $2 \mathrm{~d}$ not only resulted in a significant increase of viability starting from day 2 but also in a prolongation of viability compared to untreated cells in both donors (Fig. 5C, D).

\section{Discussion}

The antitumor activity of some mAbs used as cancer therapeutics is exerted mainly through ADCC, a mechanism mediated by the binding between the constant region (fragment crystallizable, $\mathrm{Fc}$ ) of $\mathrm{mAbs}$ and the $\mathrm{Fc}$ gamma receptor IIIa (Fcy RIIIa, CD16) expressed on macrophages and NK cells. ${ }^{41-47}$ The authors have previously reported the preclinical antitumor activity of NEO-201, a tumor antigentargeting $\mathrm{mAb}$ derived from the Hollinshead allogeneic colorectal cancer vaccine platform..$^{36-40}$ In this study, they

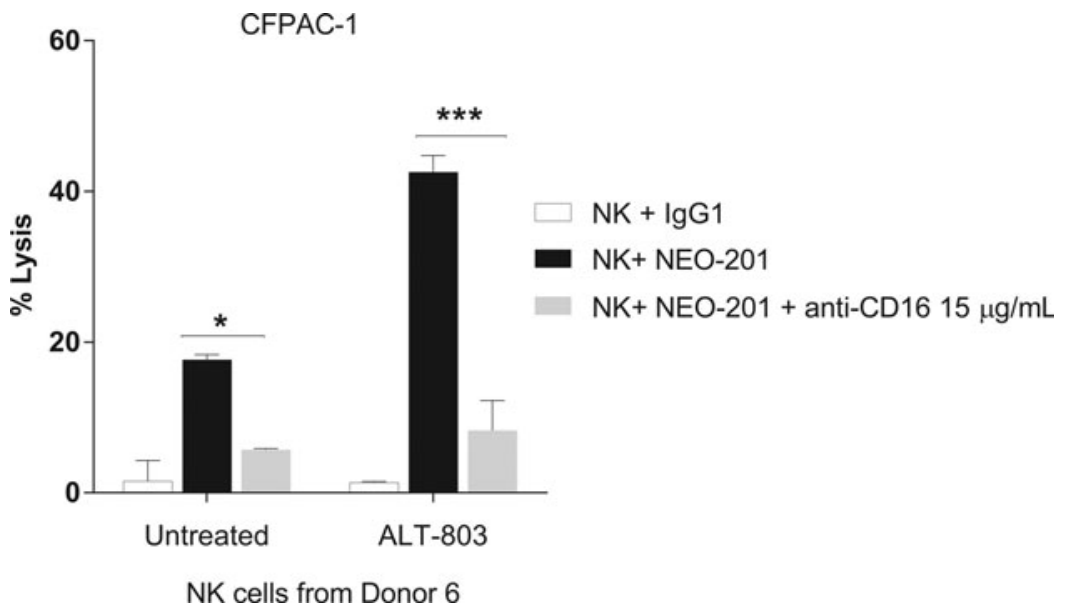

FIG. 4. ADCC mediated by NEO-201 can be blocked by the anti-CD16 antibody. CFPAC-1 cells were used as target cells in the presence of $10 \mu \mathrm{g} / \mathrm{mL}$ of NEO-201 or human IgG1 (negative control) in the ADCC assay. Purified NK cells from a healthy donor were treated with ALT-803 $(25 \mathrm{ng} / \mathrm{mL})$ or vehicle control for $48 \mathrm{~h}$ before being used as effector cells at the $\mathrm{E}: \mathrm{T}$ ratio of 12.5:1. Where applicable, NK cells were pretreated for $2 \mathrm{~h}$ with anti-CD16 blocking antibody ( $15 \mu \mathrm{g} / \mathrm{mL}) \mathrm{before}$ being used as effectors. Results are presented as mean \pm S.E.M. from three replicate wells. Asterisks denote statistical significance of $\mathrm{NK}+\mathrm{NEO}-201$ relative to $\mathrm{NK}+\mathrm{NEO}-201+$ anti-CD16 in both untreated and treated NK cells (two-way ANOVA). ${ }^{*} p<0.05 ; * * * p<0.001$. ADCC, antibody-dependent cellular cytotoxicity; NK, natural killer. 


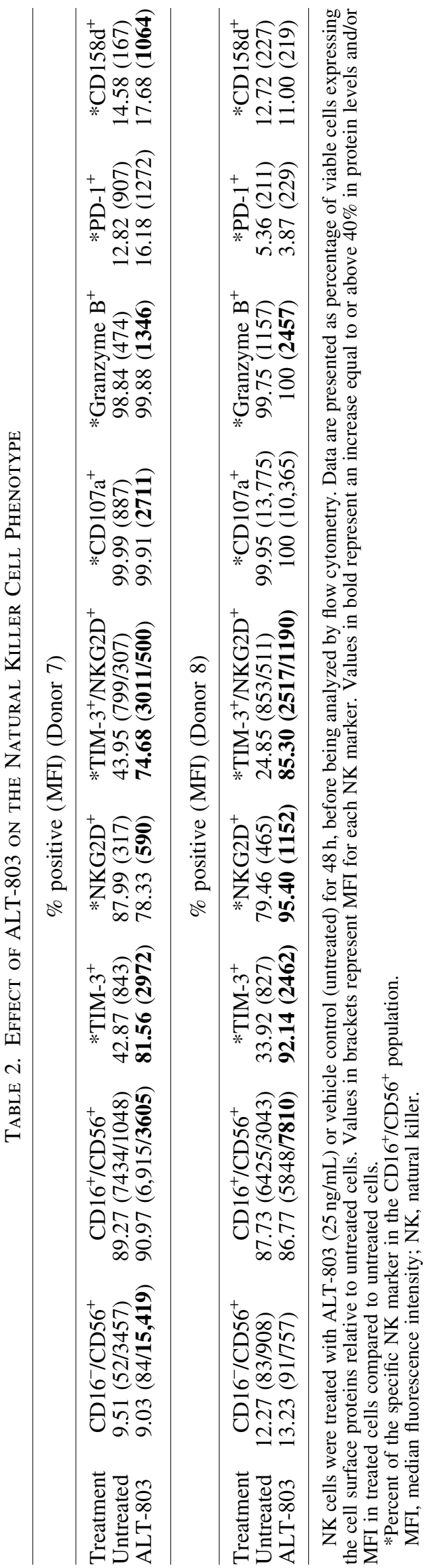

evaluated the effects of ALT-803, an IL-15 superagonist complex consisting of an IL-15 variant (IL-15N72D) bound to an IL-15 receptor $\alpha / \operatorname{IgG} 1 \mathrm{Fc}$ fusion protein, on the capacity of human NK cells to perform ADCC mediated by NEO-201.

NEO-201 is an IgG1 mAb that exhibits ADCC and CDC activity in vitro and attenuation of tumor growth in xenograft models. ${ }^{40}$ The authors demonstrated that ALT-803 significantly enhanced the ADCC mediated by NEO-201 against the highest NEO-201-positive carcinoma cell line (CFPAC-1) in a dose-dependent manner, compared with the vehicle control at both E:T ratios (Fig. 1). They also demonstrated that ALT-803, at the highest dose $(25 \mathrm{ng} / \mathrm{mL})$, significantly enhanced NEO-201-mediated ADCC at both $\mathrm{E}: \mathrm{T}$ ratios in all human carcinoma cell lines, compared to untreated cells (Fig. 2), and that ADCC mediated by NEO201 enhanced by ALT-803 is dependent on CD16 engagement (Fig. 4).

Moreover, it is interesting to note that ALT-803 retained the ability to enhance NEO-201-mediated ADCC at NEO201 doses as low as $0.1 \mu \mathrm{g} / \mathrm{mL}$. The authors also observed that NEO-201 ADCC activity at the lowest dose in presence of ALT-803 was higher than ADCC activity achieved by NEO-201 alone at the highest dose (Fig. 3), suggesting that ALT-803 could decrease the dose of NEO-201 required to achieve its clinical efficacy if used in a combined therapy.

To further investigate the mechanism by which ALT-803 enhances the ADCC mediated by NEO-201, the authors performed flow cytometry analysis on human NK cells after exposure to ALT-803. As shown in Table 2, the authors demonstrated that ALT-803 modulates the phenotype of human NK cells toward a more active cytotoxic function, increasing the expression of NK markers involved in $\mathrm{NK}$ cell activation and cytotoxicity (TIM-3, NKG2D, granzyme $\mathrm{B}$, and CD107a).

In another study, it has been shown that short-term ALT803 stimulation significantly increased granzyme B and perforin expression, as well as IFN- $\gamma$ production in human NK cells, resulting in increased ADCC directed by an antiCD20 mAb against B cell lymphoma cells. ${ }^{19}$

Similar results were achieved in other two studies, in which ALT-803 was found to enhance the function of NK cells against several ovarian cancer cell lines, multiple myeloma, and leukemia target cells with significant increases of CD107a, IFN- $\gamma$, and TNF- $\alpha$ expression. ${ }^{24,48}$

The cytokine IL-15 plays a crucial role in the immune system by affecting NK cell development, proliferation, cytotoxicity, and cytokine production. ${ }^{15}$

In this regard, the use of IL-15 superagonist complex (ALT-803) to enhance the NK antitumor activity has been proven to be more efficient than native IL-15. Pharmacokinetic analysis conducted in mice indicated that ALT-803 has a half-life much longer than half-life of IL-15, resulting in improved stability, longer persistence in lymphoid tissues, and enhanced antitumor activity compared to native IL-15 in vivo. ${ }^{18}$

It has been also shown that a single intravenous dose of ALT-803, but not IL-15, eliminated well-established tumors and prolonged survival of mice bearing multiple myeloma, ${ }^{22}$ and that ALT-803 has superior antitumor activity over IL-15 in mice bearing subcutaneous B16F10 melanoma and CT26 colon carcinoma metastases. ${ }^{26}$ Tissue biodistribution studies 


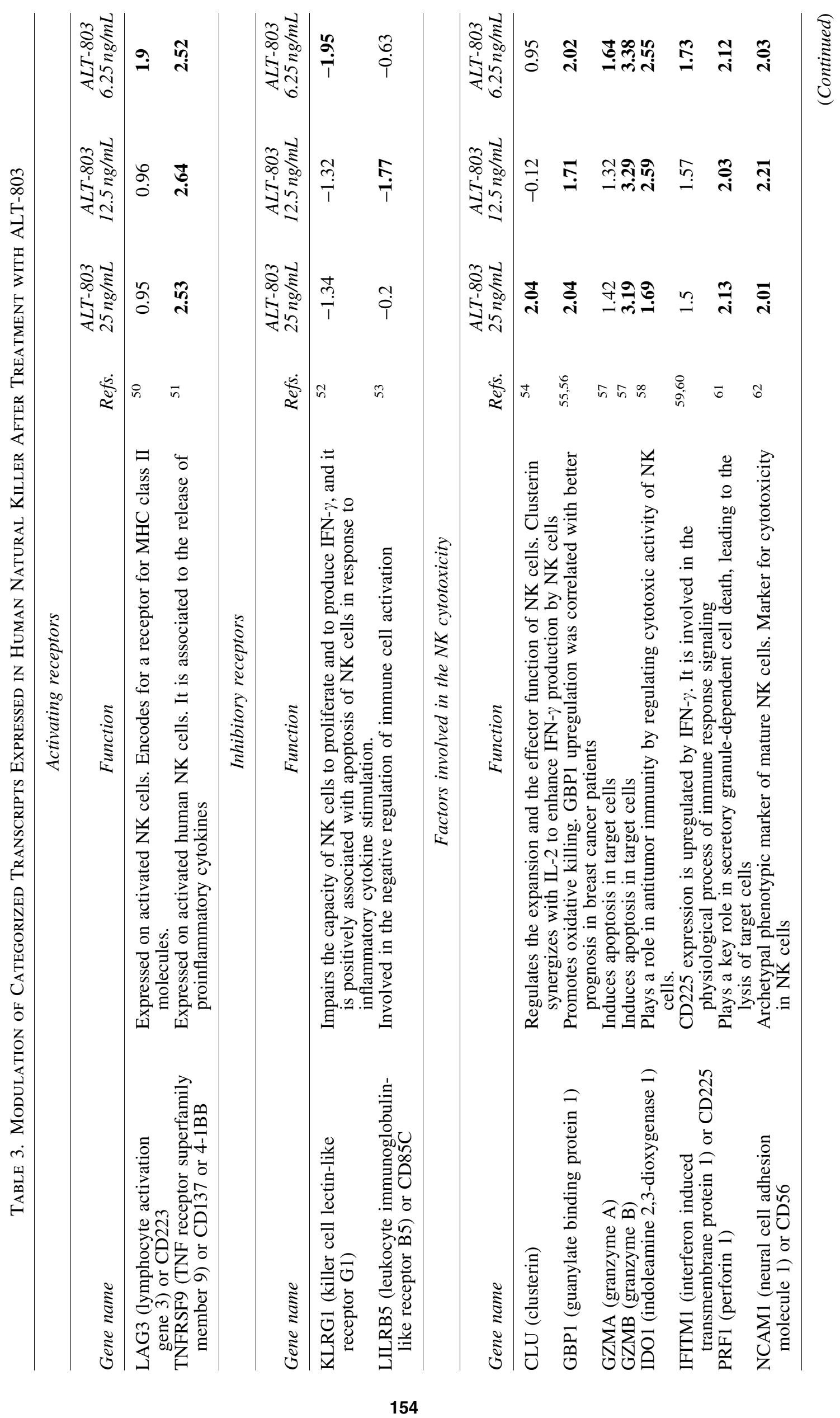




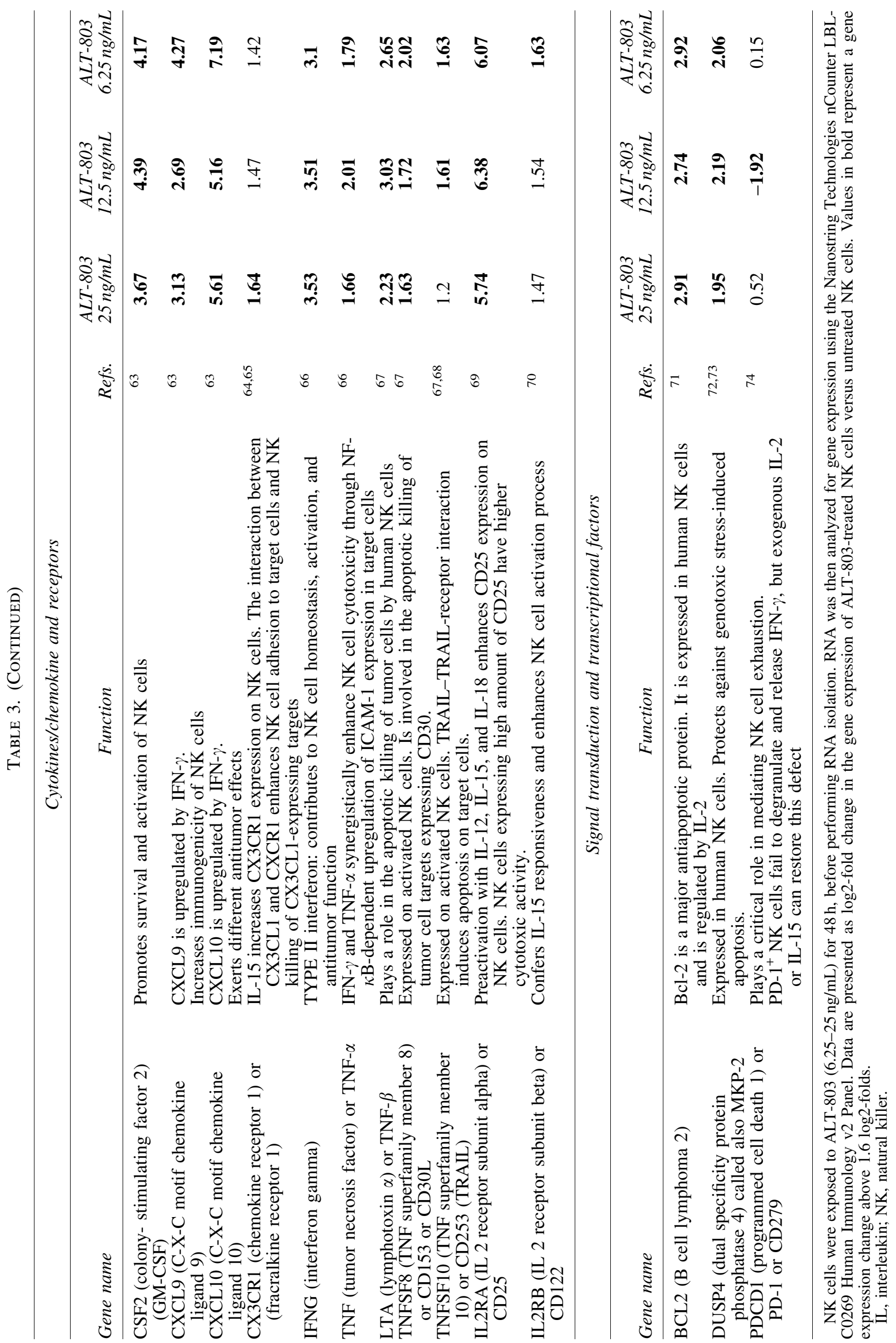



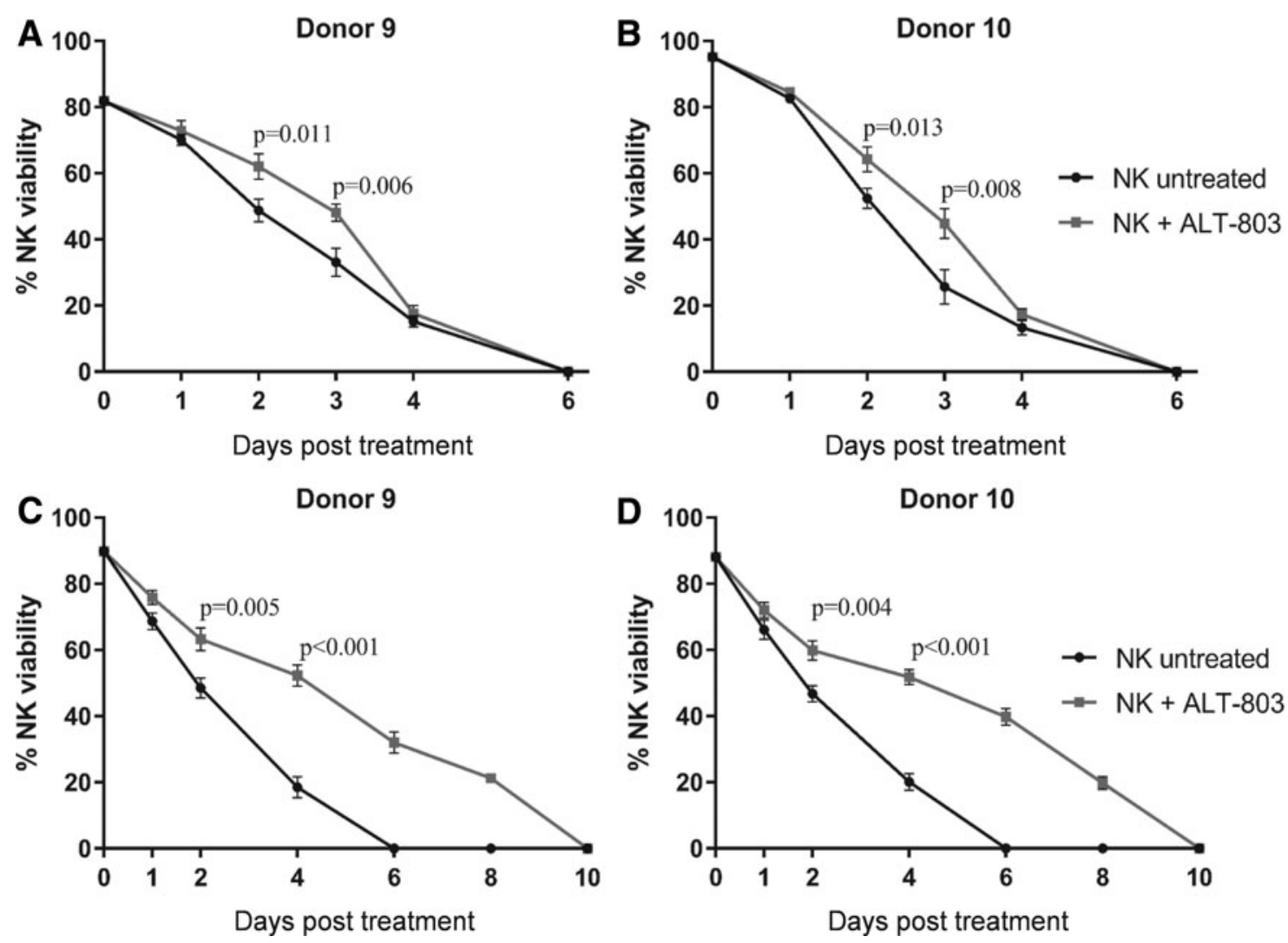

FIG. 5. ALT-803 prolongs viability of NK cells. Purified NK cells from two healthy donors were treated with ALT-803 $(25 \mathrm{ng} / \mathrm{mL})$ or vehicle control at the day 0 and then returned to incubation for $6 \mathrm{~d}$. NK cell viability was analyzed on day 1 , 2, 3, 4, and 6 post-treatment (A, B). Purified NK cells from two healthy donors were treated with ALT-803 (25 ng/mL) or vehicle control for $10 \mathrm{~d}$. ALT-803 and vehicle control were replenished every $2 \mathrm{~d}$. NK cell viability was analyzed on day 1 , $2,4,8$, and 10 post-treatment $(\mathbf{C}, \mathbf{D})$. Results are presented as mean \pm S.E.M. from three replicate wells. $p$-Values denote statistical significance relative to untreated cells (T-test). NK, natural killer.

in mice also revealed a much greater retention of ALT-803 in the lymphoid organs compared to IL-15, consistent with its highly potent immunostimulatory and antitumor activities in vivo. In addition, multidose ALT-803 administration to cynomolgus monkeys resulted in dose-dependent increases in peripheral lymphocytes, primarily NK cells, and CD8 and CD4 memory T cells. ${ }^{26}$

To better understand ALT-803's mechanism of action in the modulation of NK function, the authors performed gene expression analysis on the NK cells treated with ALT-803 using the NanoString Technologies nCounter Platform. As shown in Table 3, ALT-803 was able to modulate the phenotype of human NK cells through upregulation of gene expression of NK-activating receptors, antiapoptotic factors, and factors involved in the NK cytotoxicity, and through the downregulation of gene expression of NK-inhibiting receptors and factors involved in the in the NK cell exhaustion.

It is of interest to note that ALT-803 upregulated not only the gene expression of factors mainly involved in NK killing activity, such as granzyme A and B, perforin, IFN- $\gamma$, TNF- $\alpha$, and TNF- $\beta$, but also of other factors involved in NK cytotoxicity, such as clusterin and IDO. Clusterin is a secreted protein that regulates the expansion and the effector function of $\mathrm{NK}$ cells through the enhancement of IFN- $\gamma$ production by NK cells. ${ }^{54}$ IDO has been found to play an important role in antitumor immunity by regulating cytotoxic activity of
NK cells. Kai et al. showed that the cytotoxic activity of mouse NK cells was reduced by IDO inhibition in vitro and in vivo. ${ }^{58}$ The increased IDO gene expression the authors observed in human NK cells after exposure to ALT-803 could suggest an alternative mechanism by which ALT-803 enhances the cytotoxic activity of NK cells. ${ }^{7}$

In addition, the authors have demonstrated that ALT-803 stimulation prolongs NK cell viability (Fig. 5). This phenomenon could be, in part, due to the ability of ALT-803 to upregulate gene expression of factors involved in NK survival, such as the antiapoptotic proteins Bcl-2 and DUSP-4 (Table 3). The antiapoptotic protein bcl-2 has been found to be an activation- or proliferation-associated marker of normal NK cells, which can be induced by IL-2. ${ }^{71}$ DUSP-4, also called MKP-2 (mitogen-activated protein kinase 2), is expressed by NK cells. This kinase exerts antiapoptotic effects and plays a role in protecting cells against genotoxic stress-induced apoptosis. $^{72,73}$

The use of the cytokine IL-15 to boost the immune system against cancer cells has significant potential in cancer immunotherapy. A recent clinical trial employing Escherichia coliproduced rhIL-15, administered to patients with metastatic malignant melanoma or metastatic renal cell cancer, demonstrated safety of IL-15 treatment of patients with metastatic malignancy. IL-15 administration markedly affected the function and proliferation NK cells in these cancer patients. ${ }^{17}$ 
Promising preclinical data on the use of ALT-803 as an anticancer drug have spurred interest in using it in the clinic. Several clinical trials are ongoing to evaluate the safety and efficacy of ALT-803 alone or in combination with conventional cancer treatments.

For example, a phase I clinical trial will investigate the safety and immunogenicity, immunomodulatory properties, and clinical benefits of treatment with weekly doses of ALT803 in patients with surgically incurable advanced solid tumors, including melanoma and renal cell, nonsmall cell lung and squamous cell, and head and neck cancer. ${ }^{28}$ Recruiting clinical trials will also evaluate the efficacy of ALT803 as a therapy for the treatment of ovarian cancer, acute myelogenous leukemia, myelodysplastic syndrome, and relapsed or refractory multiple myeloma. ${ }^{29-31}$ ALT-803 will also be administered in combination with pembrolizumab or nivolumab in patients with advanced or metastatic nonsmall cell lung cancer, who have failed treatment with PD-1 checkpoint inhibitor therapy ${ }^{32}$; with rituximab in patients with relapse/refractory indolent B cell non-Hodgkin lymphoma ${ }^{33}$; with Intravesical BCG in patients with BCGunresponsive high-grade nonmuscle invasive bladder cancer ${ }^{34}$; and with ETBX-011 (Ad5 [E1-, E2b-]-CEA(6D)) vaccine in subjects having CEA-expressing cancer. ${ }^{35}$

\section{Conclusions}

This investigation has demonstrated that ALT-803 significantly enhanced the ADCC activity mediated by NEO201 against NEO-201-positive human carcinoma cells. The enhancement of NEO-201-mediated ADCC may be due to the ability of ALT-803 to increase the expression of TIM3, NKG2D, granzyme $\mathrm{B}$, and $\mathrm{CD} 107 \mathrm{a}$ on $\mathrm{CD} 56^{+} / \mathrm{CD} 16^{+} \mathrm{NK}$ cells, as well as to its capacity to upregulate gene expression of NK-activating receptors, factors involved in the NK cytotoxicity, and antiapoptotic factors.

The improved stability and enhanced antitumor activity of ALT-803 compared to native IL-15 in vivo offer a good chance to use it in combination with NEO-201 in clinic. NEO-201 pharmacokinetics evaluation in nonhuman primates showed that NEO-201 half-life was 167 or $170 \mathrm{~h}$ at the 20 or $49 \mathrm{mg} / \mathrm{kg}$ dose, respectively. ${ }^{40}$

The long permanence in the bloodstream of both drugs suggest that ALT-803 could enhance the NEO-201 antitumor activity in vivo in humans, supporting rationale for the clinical development of the combination therapy using NEO-201 and ALT-803 to treat patients with a broad variety of carcinomas.

\section{Acknowledgments}

This research was funded by Precision Biologics, Inc. The authors thank Peter Sieling and Kayvan Niazi for their assistance in the preparation of this article.

\section{Authors' Contributions}

Conception and design: M.F., J.M.D., P.M.A., and K.Y.T.; Development of methodology: M.F., J.M.D., P.M.A., and K.Y.T.; Acquisition of data: M.F. and J.M.D.; Analysis and interpretation of data: M.F., J.M.D., C.M.A., P.M.A., and K.Y.T.; Writing, review, and revision of article: M.F., J.M.D., H.C.W., C.M.A., P.M.A., and K.Y.T.; Ad- ministrative, technical, and material support: H.C.W., C.M.A., P.M.A., and K.Y.T.; Study supervision: P.M.A. and K.Y.T. All coauthors have reviewed and approved of the article before submission.

\section{Disclosure Statement}

M.F., J.M.D., P.M.A., and K.Y.T. are employees of Precision Biologics, Inc. P.M.A. has ownership interest in Precision Biologics, Inc. H.C.W. is an employee and has ownership interest in Altor BioScience Corporation. C.M.A. has no conflict of interests to declare.

\section{References}

1. Ferlay J, Soerjomataram I, Dikshit R, et al. Cancer incidence and mortality worldwide: Sources, methods and major patterns in GLOBOCAN 2012. Int J Cancer 2015;136:E359.

2. Torre LA, Bray F, Siegel RL, et al. Global cancer statistics, 2012. CA Cancer J Clin 2015;65:87.

3. Bodey B, Siegel SE, Kaiser HE. Human cancer detection and immunotherapy with conjugated and non-conjugated monoclonal antibodies. Anticancer Res 1996;16:661.

4. Mittal D, Gubin MM, Schreiber RD, et al. New insights into cancer immunoediting and its three component phasesElimination, equilibrium and escape. Curr Opin Immunol 2014;27:16.

5. Dunn GP, Old LJ, Schreiber RD. The three Es of cancer immunoediting. Annu Rev Immunol 2004;22:329.

6. Schuster M, Nechansky A, Kircheis R. Cancer immunotherapy. Biotechnol J 2006;1:138.

7. Jochems C, Fantini M, Fernando RI, et al. The IDO1 selective inhibitor epacadostat enhances dendritic cell immunogenicity and lytic ability of tumor antigen-specific $\mathrm{T}$ cells. Oncotarget 2016;7:37762.

8. Gabitzsch ES, Tsang KY, Palena C, et al. The generation and analyses of a novel combination of recombinant adenovirus vaccines targeting three tumor antigens as an immunotherapeutic. Oncotarget 2015;6:31344.

9. Tsang KY, Fantini M, Fernando RI, et al. Identification and characterization of enhancer agonist human cytotoxic $\mathrm{T}$ cell epitopes of the human papillomavirus type 16 (HPV16) E6/E7. Vaccine 2017;35:2605.

10. Topalian SL, Weiner GJ, Pardoll DM. Cancer immunotherapy comes of age. J Clin Oncol 2011;29:4828.

11. Gross E, Sunwoo JB, Bui JD. Cancer immunosurveillance and immunoediting by natural killer cells. Cancer J 2013; 19:483.

12. Miller JS, Soignier Y, Panoskaltsis-Mortari A, et al. Successful adoptive transfer and in vivo expansion of human haploidentical NK cells in patients with cancer. Blood 2005;105:3051.

13. Ljunggren HG, Malmberg KJ. Prospects for the use of NK cells in immunotherapy of human cancer. Nat Rev Immunol 2007;7:329.

14. Berrien-Elliott MM, Romee R, Fehniger TA. Improving natural killer cell cancer immunotherapy. Curr Opin Organ Transplant 2015;20:671.

15. Fehniger TA, Caligiuri MA. Interleukin 15: Biology and relevance to human disease. Blood 2001;97:14.

16. Ali AK, Nandagopal N, Lee SH. IL-15-PI3K-AKT-mTOR: A critical pathway in the life journey of natural killer cells. Front Immunol 2015;6:355.

17. Conlon KC, Lugli E, Welles HC, et al. Redistribution, hyperproliferation, activation of natural killer cells and 
CD8 T cells, and cytokine production during first-in-human clinical trial of recombinant human interleukin-15 in patients with cancer. J Clin Oncol 2015;33:74.

18. Han KP, Zhu X, Liu B, et al. IL-15:IL-15 receptor alpha superagonist complex: High-level co-expression in recombinant mammalian cells, purification and characterization. Cytokine 2011;56:804.

19. Rosario M, Liu B, Kong L, et al. The IL-15-based ALT-803 complex enhances Fc $\gamma$ RIIIa-triggered NK cell responses and in vivo clearance of B cell lymphomas. Clin Cancer Res 2016;22:596.

20. Liu B, Kong L, Han K, et al. A novel fusion of ALT-803 (interleukin (IL)-15 superagonist) with an antibody demonstrates antigen-specific antitumor responses. J Biol Chem 2016;291:23869.

21. Jochems C, Tritsch SR, Pellom ST, et al. Analyses of functions of an anti-PD-L1/TGF $\beta$ R2 bispecific fusion protein (M7824). Oncotarget 2017;8:75217.

22. Xu W, Jones M, Liu B, et al. Efficacy and mechanism-ofaction of a novel superagonist interleukin-15: Interleukin15 receptor $\alpha \mathrm{Su} / \mathrm{Fc}$ fusion complex in syngeneic murine models of multiple myeloma. Cancer Res 2013;73:3075.

23. Mathios D, Park CK, Marcus WD, et al. Therapeutic administration of IL-15 superagonist complex ALT-803 leads to long-term survival and durable antitumor immune response in a murine glioblastoma model. Int J Cancer 2016;138:187.

24. Felices M, Chu S, Kodal B, et al. IL-15 super-agonist (ALT-803) enhances natural killer (NK) cell function against ovarian cancer. Gynecol Oncol 2017;145:453.

25. Kim PS, Kwilas AR, Xu W, et al. IL-15 superagonist/IL$15 \mathrm{R} \alpha \mathrm{Sushi}-\mathrm{Fc}$ fusion complex (IL-15SA/IL-15R $\alpha \mathrm{Su}-\mathrm{Fc}$; ALT-803) markedly enhances specific subpopulations of NK and memory CD8+ T cells, and mediates potent antitumor activity against murine breast and colon carcinomas. Oncotarget 2016;7:16130.

26. Rhode PR, Egan JO, Xu W, et al. Comparison of the super agonist complex, ALT-803, to IL-15 as cancer immunotherapeutics in animal models. Cancer Immunol Res 2016;4:49.

27. Gomes-Giacoia E, Miyake M, Goodison S, et al. Intravesical ALT-803 and BCG treatment reduces tumor burden in a carcinogen induced bladder cancer rat model; a role for cytokine production and NK cell expansion. PLoS One 2014;9:e96705.

28. ClinicalTrials.gov. A phase 1 study of the clinical and immunologic effects of ALT-803 in patients with advanced solid tumors. Identifier NCT01946789. 2013. Online document at https://clinicaltrials.gov/ct2/show/NCT01946789?term= ALT-803\&rank=5 Accessed on July 30, 2018.

29. ClinicalTrials.gov. IP ALT-803 followed by SQ ALT-803 for ovarian cancer. Identifier NCT03054909. 2017. Online document at https://clinicaltrials.gov/ct2/show/NCT03054909? term=ALT-803\&rank=6 Accessed on July 30, 2018.

30. ClinicalTrials.gov. QUILT-3.035: Relapse prophylaxis with ALT-803 for AML and MDS pts following allo HSCT. Identifier NCT02989844. 2016. Online document at https://clinicaltrials.gov/ct2/show/NCT02989844?term= ALT-803\&rank=7 Accessed on July 30, 2018.

31. ClinicalTrials.gov. A Study of ALT-803 in patients with relapsed or refractory multiple myeloma. Identifier NCT02099539. 2014. Online document at https://clinical trials.gov/ct2/show/NCT02099539?term=ALT-803\&rank=9 Accessed on July 30, 2018.

32. ClinicalTrials.gov. QUILT-3.055: A study of ALT-803 in combination with Pembrolizumab or Nivolumab in pa- tients with advanced or metastatic non-small cell lung cancer. Identifier NCT03228667. 2017. Online document at https:/clinicaltrials.gov/ct2/show/NCT03228667?term= ALT-803\&rank=12 Accessed on July 30, 2018.

33. ClinicalTrials.gov. QUILT-3.002: ALT-803 in patients with relapse/refractory iNHL in conjunction with Rituximab. Identifier: NCT02384954. 2015. Online document at https://clinicaltrials.gov/ct2/show/NCT02384954?term= ALT-803\&draw=2\&rank=11 Accessed on July 30, 2018.

34. ClinicalTrials.gov. QUILT-3.032: A multicenter clinical trial of intravesical Bacillus Calmette-Guerin (BCG) in combination with ALT-803 in patients with BCG unresponsive high grade non-muscle invasive bladder cancer. Identifier: NCT03022825. 2017. Online document at https:// clinicaltrials.gov/ct2/show/NCT03022825?term=ALT-803\& rank=10 Accessed on July 30, 2018.

35. ClinicalTrials.gov. QUILT-3.040: ETBX-011 (Ad5 [E1-, E2b-]-CEA(6D)) vaccine in combination with ALT-803 (super-agonist IL-15) in subjects having CEA-expressing cancer. Identifier: NCT03127098. 2017. Online document at https://clinicaltrials.gov/ct2/show/NCT03127098?term= ALT-803\&rank=8 Accessed on July 30, 2018.

36. Hollinshead A, Glew D, Bunnag B, et al. Skin-reactive soluble antigen from intestinal cancer-cell-membranes and relationship to carcinoembryonic antigens. Lancet 1970;1: 1191.

37. Hollinshead AC, McWright CG, Alford TC, et al. Separation of skin reactive intestinal cancer antigen from the carcinoembryonic antigen of Gold. Science 1972;177:887.

38. Hollinshead A, Elias EG, Arlen M, et al. Specific active immunotherapy in patients with adenocarcinoma of the colon utilizing tumor-associated antigens (TAA). A phase I clinical trial. Cancer 1985;56:480.

39. Zeligs K, Arlen PM, Tsang KY, et al: Preclinical characterization of a novel monoclonal antibody targeting a neoantigen expressed in ovarian and GI malignancies. Cancer Res 2017;77:3025.

40. Fantini M, David JM, Saric O, et al. Preclinical characterization of a novel monoclonal antibody NEO-201 for the treatment of human carcinomas. Front Immunol 2018;8: 1899.

41. Seidel UJ, Schlegel P, Lang P. Natural killer cell mediated antibody-dependent cellular cytotoxicity in tumor immunotherapy with therapeutic antibodies. Front Immunol 2013;4:76.

42. Petricevic B, Laengle J, Singer J, et al. Trastuzumab mediates antibody-dependent cell-mediated cytotoxicity and phagocytosis to the same extent in both adjuvant and metastatic HER2/neu breast cancer patients. J Transl Med 2013;11:307.

43. Dall'Ozzo S, Tartas S, Paintaud G, et al. Rituximabdependent cytotoxicity by natural killer cells: Influence of FCGR3A polymorphism on the concentration-effect relationship. Cancer Res 2004;64:4664.

44. Levy EM, Sycz G, Arriaga JM, et al. Cetuximab-mediated cellular cytotoxicity is inhibited by HLA-E membrane expression in colon cancer cells. Innate Immun 2009;15:91.

45. Kawaguchi Y, Kono K, Mimura K, et al. Cetuximab induce antibody-dependent cellular cytotoxicity against EGFRexpressing esophageal squamous cell carcinoma. Int J Cancer 2007;120:781.

46. López-Albaitero A, Lee SC, Morgan S, et al. Role of polymorphic Fc gamma receptor IIIa and EGFR expression level in cetuximab mediated, NK cell dependent in vitro 
cytotoxicity of head and neck squamous cell carcinoma cells. Cancer Immunol Immunother 2009;58:1853.

47. Boyerinas B, Jochems C, Fantini M, et al. AntibodyDependent Cellular Cytotoxicity activity of a novel antiPD-L1 antibody Avelumab (MSB0010718C) on human tumor cells. Cancer Immunol Res 2015;3:1148.

48. Wagner JA, Rosario M, Romee R, et al. CD56bright NK cells exhibit potent antitumor responses following IL-15 priming. J Clin Invest 2017;127:4042.

49. Fujii R, Jochems C, Tritsch SR, et al. An IL-15 superagonist/IL-15R $\alpha$ fusion complex protects and rescues NK cell-cytotoxic function from TGF- $\beta 1$-mediated immunosuppression. Cancer Immunol Immunother 2018;67:675.

50. Huard B, Tournier M, Triebel F. LAG-3 does not define a specific mode of natural killing in human. Immunol Lett 1998;61:109.

51. Lin W, Voskens CJ, Zhang X, et al. Fc-dependent expression of CD137 on human NK cells: Insights into "agonistic" effects of anti-CD137 monoclonal antibodies. Blood 2008;112:699.

52. Wang JM, Cheng YQ, Shi L, et al. KLRG1 negatively regulates natural killer cell functions through the Akt pathway in individuals with chronic hepatitis $\mathrm{C}$ virus infection. J Virol 2013;87:11626.

53. Kang X, Kim J, Deng M, et al. Inhibitory leukocyte immunoglobulin-like receptors: Immune checkpoint proteins and tumor sustaining factors. Cell Cycle 2016;15:25.

54. Sonn $\mathrm{CH}, \mathrm{Yu} \mathrm{YB}$, Hong YJ, et al. Clusterin synergizes with IL-2 for the expansion and IFN- $\gamma$ production of natural killer cells. J Leukoc Biol 2010;88:955.

55. Ascierto ML, Kmieciak M, Idowu MO, et al. A signature of immune function genes associated with recurrence-free survival in breast cancer patients. Breast Cancer Res Treat 2012;131:871.

56. Ascierto ML, Idowu MO, Zhao Y, et al. Molecular signatures mostly associated with $\mathrm{NK}$ cells are predictive of relapse free survival in breast cancer patients. J Transl Med 2013;11:145.

57. Bratke K, Kuepper M, Bade B, et al. Differential expression of human granzymes $\mathrm{A}, \mathrm{B}$, and $\mathrm{K}$ in natural killer cells and during CD8+ T cell differentiation in peripheral blood. Eur J Immunol 2005;35:2608.

58. Kai S, Goto $\mathrm{S}$, Tahara $\mathrm{K}$ et al. Inhibition of indoleamine 2,3-dioxygenase suppresses NK cell activity and accelerates tumor growth. J Exp Ther Oncol 2003;3:336.

59. Ma D, Cao W, Kapur A, et al. Differential expression of proteins in naïve and IL-2 stimulated primary human NK cells identified by global proteomic analysis. J Proteomics 2013;91:151.

60. Lewin AR, Reid LE, McMahon M, et al. Molecular analysis of a human interferon-inducible gene family. Eur $\mathbf{J}$ Biochem 1991;199:417.
61. Osińska I, Popko K, Demkow U. Perforin: an important player in immune response. Cent Eur J Immunol 2014;39: 109.

62. Van Acker HH, Capsomidis A, Smits EL, et al. CD56 in the immune system: More than a marker for cytotoxicity? Front Immunol 2017;8:892.

63. Campbell AR, Regan K, Bhave N, et al. Gene expression profiling of the human natural killer cell response to Fc receptor activation: unique enhancement in the presence of interleukin-12. BMC Med Genomics 2015;8:66.

64. Sechler JM, Barlic J, Grivel JC et al. IL-15 alters expression and function of the chemokine receptor CX3CR1 in human NK cells. Cell Immunol 2004;230:99.

65. Zhang $\mathrm{X}$, Wei $\mathrm{H}$, Wang $\mathrm{H}$. Involvement of interaction between Fractalkine and CX3CR1 in cytotoxicity of natural killer cells against tumor cells. Oncol Rep 2006;15:485.

66. Wang R, Jaw JJ, Stutzman NC, et al. Natural killer cellproduced IFN- $\gamma$ and TNF- $\alpha$ induce target cell cytolysis through up-regulation of ICAM-1. J Leukoc Biol 2012;91: 299.

67. Kashii Y, Giorda R, Herberman RB, et al. Constitutive expression and role of the TNF family ligands in apoptotic killing of tumor cells by human NK cells. J Immunol 1999; 163:5358.

68. Zamai L, Ahmad M, Bennett IM, et al. Natural killer (NK) cell-mediated cytotoxicity: Differential use of TRAIL and Fas ligand by immature and mature primary human NK cells. J Exp Med 1998;188:2375.

69. Leong JW, Chase JM, Romee R, et al. Pre-activation with IL-12, IL-15, and IL-18 induces CD25 and a functional highaffinity IL-2 receptor on human cytokine-induced memorylike natural killer cells. Biol Blood Marrow Transplant 2014; 20:463.

70. Elpek KG, Rubinstein MP, Bellemare-Pelletier A, et al. Mature natural killer cells with phenotypic and functional alterations accumulate upon sustained stimulation with IL15/IL-15Ralpha complexes. Proc Natl Acad Sci USA 2010; 107:21647.

71. Jiang S, Munker R, Andreeff M. Bcl-2 is expressed in human natural killer cells and is regulated by interleukin-2. Nat Immun 1996;15:312.

72. Odman-Ghazi SO, Abraha A, Isom ET, et al. Dibutyltin activates MAP kinases in human natural killer cells, in vitro. Cell Biol Toxicol 2010;26:469.

73. Cadalbert L, Sloss CM, Cameron P, et al. Conditional expression of MAP kinase phosphatase-2 protects against genotoxic stress-induced apoptosis by binding and selective dephosphorylation of nuclear activated $\mathrm{c}$-jun $\mathrm{N}$-terminal kinase. Cell Signal 2005;17:1254.

74. Beldi-Ferchiou A, Lambert M, Dogniaux S, et al. PD-1 mediates functional exhaustion of activated NK cells in patients with Kaposi sarcoma. Oncotarget 2016;7:72961. 